\title{
Effects of ileal resection on biliary lipids and bile acid composition in patients with Crohn's disease
}

\author{
A Lapidus, K Einarsson
}

\begin{abstract}
Biliary lipid composition, cholesterol saturation, and bile acid pattern were determined in fasting duodenal bile of $\mathbf{1 0}$ patients (four men and six women, mean age 41 years) with Crohn's disease and a history of ileal resection (mean $64 \mathrm{~cm}$ ). The data were compared with corresponding values in a group of healthy subjects. None of the patients with Crohn's disease had supersaturated bile. Cholesterol saturation was significantly lower in the patients with Crohn's disease than in the healthy subjects. The molar percentage of cholesterol was also lower among the patients but there was no significant difference. The molar percentages of phospholipids and bile acids were normal. Bile acid composition in the patients with ileal resection was characterised by a signficant decrease in the deoxycholic acid fraction and a pronounced increase in the ursodeoxycholic acid fraction compared with the healthy subjects. The surprisingly high percentage of ursodeoxycholic acid may contribute to the low degree of cholesterol saturation in bile. Based on these results patients with Crohn's disease should not have an increased risk of cholesterol gall stone formation.
\end{abstract}

Bile acids are formed in the liver from cholesterol. They are excreted in bile and participate in the enterohepatic circulation as primary bile acids (chenodeoxycholic acid, cholic acid) and secondary bile acids (deoxycholic acid, lithocholic acid, ursodeoxycholic acid). ${ }^{12}$ About $95-99 \%$ of bile acids are reabsorbed from the intestine. This occurs mainly by an active process in the distal part of the ileum and to a less extent by passive diffusion along the whole intestine.

Ileal resection leads to bile acid malabsorption and altered lipid composition. ${ }^{34}$ This might result in 'bile acid deficiency' in the enterohepatic circulation and consequently a relative excess of cholesterol and cholesterol supersaturated bile. ${ }^{5}$ Cholesterol supersaturated bile has been pro-

\begin{tabular}{|c|c|c|c|c|c|c|c|}
\hline $\begin{array}{l}\text { Patient } \\
\text { No }\end{array}$ & Sex & $\begin{array}{l}\text { Age } \\
\text { (years) }\end{array}$ & $\begin{array}{l}\text { Weight } \\
(\mathrm{kg})\end{array}$ & $\begin{array}{l}\text { Relative } \\
\text { weight }(\%)^{\star}\end{array}$ & $\begin{array}{l}\text { Serum cholesterol } \\
(\mathrm{mmol} / \mathrm{l})\end{array}$ & $\begin{array}{l}\text { Serum triglycerides } \\
(\text { mmolll })\end{array}$ & $\begin{array}{l}\text { Ileum resection } \\
(\mathrm{cm})\end{array}$ \\
\hline $\begin{array}{c}1 \\
2 \\
3 \\
4 \\
5 \\
6 \\
7 \\
8 \\
9 \\
10 \\
\text { Mean }\end{array}$ & $\begin{array}{l}M \\
M \\
M \\
M \\
F \\
F \\
F \\
F \\
F \\
F\end{array}$ & $\begin{array}{l}39 \\
57 \\
22 \\
46 \\
37 \\
23 \\
61 \\
22 \\
65 \\
37 \\
41\end{array}$ & $\begin{array}{l}76 \\
72 \\
62 \\
72 \\
68 \\
54 \\
54 \\
58 \\
65 \\
50 \\
63\end{array}$ & $\begin{array}{r}103 \\
95 \\
80 \\
97 \\
105 \\
86 \\
95 \\
94 \\
114 \\
74 \\
94\end{array}$ & $\begin{array}{l}5 \cdot 2 \\
3 \cdot 9 \\
2 \cdot 5 \\
6 \cdot 7 \\
4 \cdot 6 \\
4 \cdot 0 \\
3 \cdot 0 \\
3 \cdot 6 \\
4 \cdot 9 \\
2 \cdot 4 \\
4 \cdot 1\end{array}$ & $\begin{array}{l}1.1 \\
0.7 \\
1.0 \\
1.8 \\
1.1 \\
0.7 \\
1.4 \\
1.5 \\
1.1 \\
1.2 \\
1.2\end{array}$ & $\begin{array}{r}20 \\
30 \\
50 \\
160 \\
20 \\
35 \\
50 \\
70 \\
100 \\
105 \\
64\end{array}$ \\
\hline
\end{tabular}

${ }^{\star}$ Calculated (body weight $\left.(\mathrm{kg}) / \mathrm{height}(\mathrm{cm})-100\right) \times 100 \%$.

Division of

Hepatol of Medicine, Depart Institutet at Huddinge University Hospital Huddinge, Sweden K Einars

Correspondence to: Annika Lapidus, Department of Medicine, Huddinge University Hospital, S-141 86 Huddinge, Sweden

Accepted for publication 11 February 1991 posed as an important factor in cholesterol gall stone formation. ${ }^{6}$ Since there is an increased prevalence of gall stones among patients with Crohn's disease, particularly those with a history of ileal resection, such patients might be expected to have a high degree of cholesterol saturation. ${ }^{7-10}$

The aim of this study was to determine lipid composition, bile acid composition, and cholesterol saturation in patients with Crohn's disease who had previously undergone ileal resection of various lengths to evaluate whether they have an increased risk of developing cholesterol gall stones.

\section{Methods}

PATIENTS

Ten patients (four men and six women; mean age 41 years) with a history of ileal resection due to Crohn's disease were included in the study (Table I). The length of resected ileum varied from 20 to $160 \mathrm{~cm}$ with an average of $64 \mathrm{~cm}$. None had clinical or laboratory evidence of active disease. All were of normal weight and normolipidaemic. None had a history of gall stone disease. All had normal liver and renal function tests. One patient was treated with sulphasalazine while the other patients took no drugs that are known to interfere with lipid or bile acid metabolism.

Informed consent to participate was obtained from each patient. The ethical aspects of the study were approved by the Ethical Committee at Huddinge University Hospital.

\section{EXPERIMENTAL PROCEDURE}

The patients were hospitalised for the study and fed the regular hospital diet containing about $0.5 \mathrm{mmol}$ cholesterol per day. Bile was collected on the two following days. An oroduodenal tube was introduced in the morning after an overnight fast. Gall bladder contraction was stimulated by intravenous injection of cholecystokinin, and $5 \mathrm{ml}$ of concentrated gall bladder bile was obtained through the tube. The tube was removed and the same procedure repeated the following day.

The lipid composition (cholesterol, phospholipids, and bile acids) and bile acid composition of bile were determined. The cholesterol saturation was calculated. The results were compared to corresponding data in a large group of healthy subjects previously reported. ${ }^{11}$

BILIARY LIPID COMPOSITION AND CHOLESTEROL SATURATION

For measurements of cholesterol and phospho- 
lipids a portion of the duodenal bile was immediately extracted with 20 volumes of chloroform-methanol 2:1 (vol/vol). Cholesterol was determined by an enzymatic method ${ }^{12}$ and phospholipids by the method of Rouser et al. ${ }^{13}$ The total bile acid concentration was determined using a 3- $\alpha$-hydroxysteroid dehydrogenase assay. ${ }^{14}$ Cholesterol saturation was calculated according to Carey's method with the total lipid concentration assumed to be $10 \mathrm{~g} / 100 \mathrm{ml}$ in concentrated fasting duodenal bile. ${ }^{15}$ Cholesterol saturation was also calculated with a correction factor for ursodeoxycholic acid rich bile. ${ }^{15}$

\section{BILIARY BILE ACID COMPOSITION}

The duodenal bile samples were hydrolysed with $1 \mathrm{~mol} / \mathrm{l}$ potassium hydroxide in closed steel tubes for 12 hours at $110^{\circ} \mathrm{C}$. The deconjugated bile acids were extracted with ethyl ether after acidification with $6 \mathrm{~mol} / 1 \mathrm{HCl}$ to $\mathrm{pH} 1$. An aliquot of the deconjugated bile acids was methylated, trimethylsilylated, and analysed by gas-liquid chromatography using a $1 \%$ HiEff BP8 column as described previously. ${ }^{16}$

\section{STATISTICAL ANALYSIS}

Data are presented as mean (SEM). Comparisons of data between patients and healthy subjects were calculated by using Student's $t$ test. Probability values $<0.05$ were considered to be significant.

\section{Results}

Data for biliary lipid composition and cholesterol saturation are given in Table II. The molar percentage of cholesterol was lower, but not significantly lower, in the patients with ileal resection than in the healthy control subjects $(4.6$ molar $\% v 5.6$ molar $\% \mathrm{p}<0 \cdot 1)$. There were no significant differences in the molar percentages of phospholipids or bile acids between the patients and the healthy subjects.

Cholesterol saturation was significantly lower in the patients than in the control subjects $(64 \% v$ $86 \%, \mathrm{p}<0.005)$. None of the 10 patients had supersaturated bile. As cholesterol saturation of bile increases with age, " we related the data for our patients to the data for control subjects of corresponding age. As the Figure shows, in all but one patient cholesterol saturation of bile was below normal.

Biliary bile acid composition differed between the patients and the control subjects (Table III). Thus the percentage of deoxycholic acid was significantly lower in the patients than in the control subjects $(12.7 \% v 23.4 \% \mathrm{p}<0.05)$. Surprisingly, the amount of ursodeoxycholic acid was significantly higher in the patients than in the control subjects $(10.3 \% v 0.7 \% \mathrm{p}<0.001)$. There were no correlations between the length of resected ileum and cholesterol saturation percentage of ursodeoxycholic acid.

\section{Discussion}

The results of this study clearly show that patients with a history of ileal resection due to
TABLE II Biliary lipid composition and cholesterol saturation (mean $(S E M)$

\begin{tabular}{|c|c|c|c|}
\hline & $\begin{array}{l}\text { Patients } \\
(n=10)\end{array}$ & $\begin{array}{l}\text { Healthy } \\
\text { subjects } \\
(n=60)\end{array}$ & Significance \\
\hline Cholesterol (molar \%) & $4 \cdot 6(0.5)$ & $5 \cdot 6(0 \cdot 3)$ & NS \\
\hline Phospholipids (molar \%) & $22 \cdot 4(1 \cdot 2)$ & $20 \cdot 6(0.5)$ & NS \\
\hline Bile acids (molar \%) & $73 \cdot 0(1 \cdot 7)$ & $73 \cdot 6(0 \cdot 6)$ & NS \\
\hline Cholesterol saturation (\%) & $64(6) \dagger$ & $86(3)$ & $\mathrm{p}<0.005$ \\
\hline
\end{tabular}

^Data from Einarsson et al."

NS $=$ not significant

†67 (6) \% after calculation with a correction factor for ursodeoxycholic acid rich bile.

TABLE III Biliary bile acid composition (mean (SEM))

\begin{tabular}{lccl}
\hline & $\begin{array}{l}\text { Patients } \\
(n=10)\end{array}$ & $\begin{array}{l}\text { Healthy } \\
\text { subjects } \\
(n=50)\end{array}$ & Significance \\
\hline Cholic acid (\%) & $38 \cdot 8(3 \cdot 9)$ & $\begin{array}{l}41 \cdot 2(1 \cdot 5) \\
\text { Chenodeoxycholic acid (\%) }\end{array}$ & NS \\
Deoxycholic acid (\%) & $12 \cdot 7(2 \cdot 3)$ & $34 \cdot 5(1 \cdot 2)$ & NS \\
Lithocholic acid (\%) & $1 \cdot 1(0 \cdot 8)$ & $23 \cdot 4(1 \cdot 8)$ & p $<0.05$ \\
Ursodeoxycholic acid (\%) & $10 \cdot 3(2 \cdot 8)$ & $0 \cdot 7(0 \cdot 3)$ & NS \\
& & & p $<0.001$ \\
\hline
\end{tabular}

^Data from Einarsson et al."

NS $=$ not significant.

Crohn's disease have a low molar percentage of cholesterol and low cholesterol saturation of bile. No correlation between cholesterol saturation and length of resected ileum was found. Various data on bile lithogenicity in patients with Crohn's disease have been published. Most studies have reported on a high frequency of cholesterol supersaturated bile in Crohn's disease patients with ileal resection or ileal dysfunction. $^{517-19}$ Only Färkkilä has reported that patients who had undergone ileal resection had low to normal cholesterol saturation of bile. ${ }^{20}$ Färkkilä found that the molar percentage of biliary cholesterol was inversely correlated with faecal bile acid excretion in patients with ileal resection and suggested that biliary cholesterol secretion decreases with increasing loss of bile

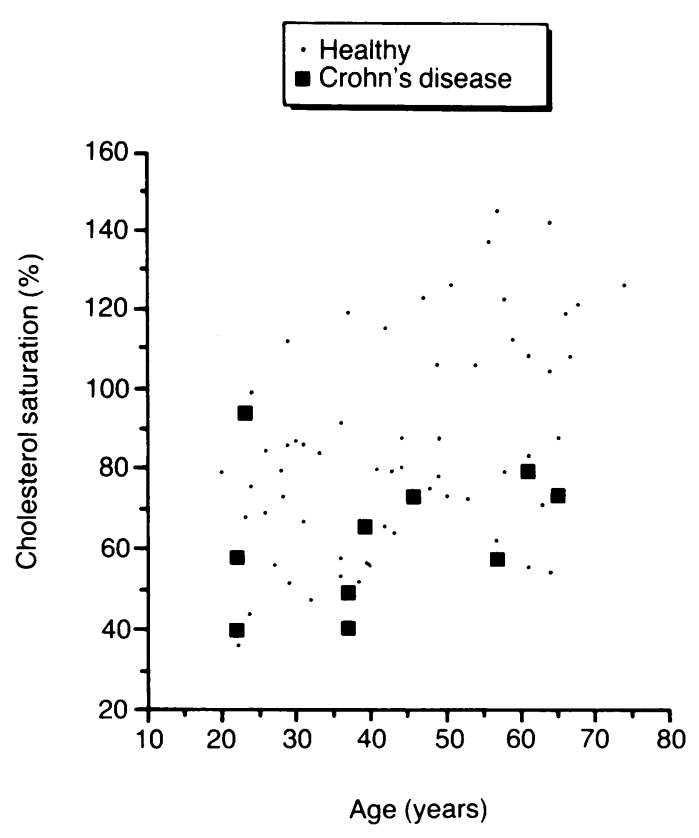

Relation between age and cholesterol saturation of bile in healthy subjects (data from Einarsson $\mathrm{et}^{\mathrm{al}}$ ") and patients with Crohn's disease with a history of ileal resection. 
acids to faeces, leading to hyposaturation of cholesterol in bile.

Bile acid composition in our patients with ileal resection was characterised by a significant decrease in the deoxycholic acid fraction and a surprisingly high percentage of ursodeoxycholic acid. There were no significant differences between the patients and healthy control subjects for cholic acid, chenodeoxycholic acid, and lithocholic acid. The decreased molar percentage of deoxycholic acid is in agreement with the results of several studies, ${ }^{4181921-23}$ but not with all. ${ }^{17245}$ Low deoxycholic acid concentrations may be due to impaired formation or conservation, or both. Probably the decrease in deoxycholic acid in patients with ileal resection is caused by reduced exposure of cholic acid to bacterial $7 \alpha$-dehydroxylase because of a shortened intestinal transit time. This is further supported by previous studies on the faecal pattern of bile acids in patients with Crohn's disease showing a pronounced low relative proportion of deoxycholic acid and an increased proportion of cholic acid. ${ }^{2326}$

Ursodeoxycholic acid is the $7 \beta$-hydroxyepimer of chenodeoxycholic acid and is usually found only in small concentrations in human bile. ${ }^{27-28}$ Previous studies in healthy subjects and in patients with Crohn's disease have shown that ursodeoxycholic acid is formed from chenodeoxycholic acid via 7-ketolithocholic acid as an intermediate. ${ }^{29-31}$ Chenodeoxycholic acid is oxidised to 7-ketolithocholic acid by bacterial enzymes in the intestine. In the liver most of the 7-ketolithocholic acid is reduced to chenodeoxycholic acid and only a little to ursodeoxycholic acid. Some chenodeoxycholic acid may also be transformed to ursodeoxycholic acid in the intestine. ${ }^{32}$

A slightly increased amount of ursodeoxycholic acid in unoperated patients with Crohn's disease has been reported by Rutgeerts and colleagues $^{2533}$ and Nishida et al. ${ }^{34}$ However, in contrast to our results Rutgeerts et $a l^{18}{ }^{19}$ found a normal concentration of ursodeoxycholic acid in patients with ileal resection. The present findings of a more than tenfold increase in the relative concentration of ursodeoxycholic acid and a concomitant decrease in deoxycholic acid in patients with Crohn's disease and ileal resection are not quite understood. One explanation may be that such patients may have an abnormal intestinal flora that favours the formation of ursodeoxycholic acid.

Treatment of patients with gall stones with ursodeoxycholic acid is associated with unsaturation of bile and may induce stone dissolution. ${ }^{28}$ The cholesterol desaturating effect of ursodeoxycholic acid is due to a decreased output of biliary cholesterol, ${ }^{36}$ which in turn is mainly explained by impaired absorption of cholesterol from the intestine. ${ }^{37-39}$ Ursodeoxycholic acid may also prolong the nucleation time of gall bladder bile, ${ }^{+0}+1$ thereby preventing cholesterol crystallisation and gall stone formation. We suggest that the increased proportion of ursodeoxycholic acid in combination with a decreased proportion of deoxycholic acid in the bile of the patients with Crohn's disease in the present study may have contributed to their low cholesterol saturation.
Our results show that there should be no increased risk of cholesterol gall stone formation in patients with Crohn's disease who have undergone ileal resection. On the other hand, in several studies an increased prevalence of gall stones among patients with ileal dysfunction has been found. ${ }^{7-10}$ How can we explain that? It may be that patients with ileal resection preferentially form pigment stones. It has been reported from studies in the prairie dog and guinea pig that ileal resection produces gall stones of pigment type. ${ }^{42+3}$

Patients with Crohn's disease who have undergone ileal resection have low cholèsterol saturation of bile to which an increased amount of ursodeoxycholic acid may contribute. Such patients should therefore not run an increased risk of cholesterol gall stone formation.

The skilful technical assistance of Ms Lisbet Benthin and Ms Ingela Svensson and manuscript preparation by Ms Catrine Olsson are gratefully acknowledged. This study was supported by Olsson are gratefully acknowledged. This study was supported by
grants from the Swedish Medical Research Council (03X-4793).

1 Hofmann AF. The enterohepatic circulation of bile acids in man. Adv Intern Med 1976; 21: 501-34.

2 Carey MC, Cahalane MJ. Enterohepatic circulation. In: Aria IM, Jakoby WB, Popper H, Schachter D, Shafritz DA, eds. The liver: biology and pathobiology. New York: Raven Press, 1988: $573-616$

3 Grundy SM, Ahrens EH Jr, Salen G. Interruption of the enterohepatic circulation of bile acids in man: comparative effects of cholestyramine and ileal exclusion on cholesterol metabolism. F Lab Clin Med 1971; 78: 94-121.

4 metabolism. F L Lab Clin Med 1971; 78: 94-121. tinal disease. Clin Gastroenterol 1976; 6: 69-89.

5 Dowling RH, Bell GD, White J. Lithogenic bile in patients with ileal dysfunction. Gut 1972;13: 415-20.

6 Admirand WH, Small DM. The physicochemical basis of cholesterol gallstone formation in man. $\mathcal{F}$ Clin Invest 1968 47: $1043-52$.

7 Heaton KW, Read AE. Gallstones in patients with disorders of the terminal ileum and disturbed bile salt metabolism. $B M \mathcal{F}$ 1969; 3: 494-6.

8 Cohen S, Kaplan M, Gottlieb L, Patterson J. Liver disease and gallstones in regional enteritis. Gastroenterology 1971; 60: 237-45.

9 Hill GL, Mair WSJ, Goligher JC. Gallstones after ileostomy and ileal resection. Gut 1975; 16:932-6.

10 Whorwell PJ, Hawkins R, Dewbury K, Wright R. Ultrasound survey of gallstones and other hepatobiliary disorders in patients with Crohn's disease. Dig Dis Sci 1984; 29: 930-3.

11 Einarsson K, Nilsell K, Leijd B, Angelin B. Influence of age on secretion of cholesterol and synthesis of bile acids by the liver. NEnglf Med 1985; 313: 277-82.

12 Roda A, Festi D, Sama C, et al. Enzymatic determination of cholesterol in bile. Clin Chim Acta 1975; 64: 337-41.

13 Rouser G, Fleischer S, Yamamoto A. Two dimensional thin layer chromatographic separation of polar lipids and determination of phospholipids by phosphorous analysis of spots. Lipids 1970; 5: 494-6.

14 Fausa O, Skålhegg BA. Quantitative determination of bile acids and their conjugates using thin-layer chromatography and a purified 3- $\alpha$-hydroxysteroid dehydrogenase. Scand f Gastroenterol 1974; 9: 249-54.

15 Carey M. Critical tables for calculating the cholesterol saturation of native bile. $\mathcal{F}$ Lipid Res 1978; 19: 945-55.

16 Angelin B. Einarsson K, Leijd B. Biliary lipid composition during treatment with different hypolipidaemic drugs. Eur Clin Invest 1979; 9: 185-90.

17 Marks JW, Conley DR, Capretta TL, et al. Gallstone prevalence and biliary lipid composition in inflammatory bowel disease. Dig Dis Sci 1977; 22: 1097-100.

18 Rutgeerts P, Ghoos Y, Vantrappen G, Fevery I. Biliary lipid composition in patients with nonoperated Crohn's disease. Dig Dis Sci 1986; 31: 27-32.

19 Rutgeerts P, Ghoos Y, Vantrappen G. Effect of partia ileocolectomy and Crohn's disease on biliary lipid secretion. Dig Dis Sci 1987; 32: 1231-8.

20 Färkkilä MA. Biliary cholesterol and lithogenicity of bile in patients after ileal resection. Surgery 1988; 104: 18-25.

21 Thaysen H, Bruusgaard A, Eriksen B. Evaluation of the efficiency of bile salt recirculation in patients with terminal leopathies by means of deoxycholate determination in duodenal aspirates. Scand f Gastroenterol 1970; 5: 39-47.

22 Mallory A, Kern F Jr, Smith J, Savage D. Patterns of bile acid and microflora in the human small intestine. I. Bile acids. Gastroenterology 1973; 64: 26-33.

23 Kruis W, Kalek HD, Stellaard F, Paumgartner G. Altered faecal bile acid pattern in patients with inflammatory bowel disease. Digestion 1986; 35: 189-98.

24 Abaurre R, Gordon SG, Mann JG, Kern F Jr. Fasting bile sal pool size and composition after ileal resection. Gastroenterology 1969; 57: 679-88. 
25 Rutgeerts P, Ghoos Y, Vantrappen G. Kinetics of primary bile acids in patients with non-operated Crohn's disease. Eur 7 Clin Invest 1982; 12: 135-43.

26 Fiasse R, Eyssen HJ, Leonard PJ, Dive CH. Faecal bile acid analysis and intestinal absorption in Crohn's disease before and after ileal resection. Eur F Clin Invest 1983; 13: 185-92.

27 Hellström K, Siövall J. On the origin of lithocholic and ursodeoxycholic acids in man. Acta Physiol Scand 1961; 51 218-23.

28 Bachrach WH, Hofmann AF. Ursodeoxycholic acid in the treatment of cholesterol lithiasis. Dig Dis Sci 1982; 27: $833-56$

29 Fromm H, Carlson GL, Hofmann AF, Farivar S, Amin P. Metabolism in man of 7-ketolithocholic acid: a precursor of Metabolism in man of 7 -ketolithocholic acid: a precursor of 1980; 239: 161-6.

30 Fromm H, Rajendra PS, Bazzoli F. Formation of ursodeoxycholic acid from chenodeoxycholic acid in the human colon: studies of the role of 7-ketolithocholic acid as an intermediate. 7 Lipid Res 1983; $24: 841-53$.

31 Miwa H, Yamamoto $M$, Nishida T, Yao T. Transformation of chenodeoxycholic acid to ursodeoxycholic acid in patien with Crohn's disease. Gastroenterology 1986; 90: 718-23.

32 Federowski T, Salen G, Tint GS, Mosbach E. Transformation of chenodeoxycholic acid and ursodeoxycholic acid by human intestinal bacteria. Gastroenterology 1979; 77 : 1068-73.

33 Vantrappen G, Ghoos Y, Rutgeerts P, Janssens J. Bile acid studies in uncomplicated Crohn's disease. Gut 1977; 18: 730-5.

34 Nishida T, Miwa H, Yamamoto M, Yao T. Bile acid absorption kinetics in Crohn's disease on elemental diet after ora administration of a stable-isotope tracer with chenodeoxycholic - 11, 12-d acid. Gut 1982; 23: 751-7.

35 Tint GS, Salen G, Shefer S. Effect of ursodeoxycholic acid and chenodeoxycholic acid on cholesterol and bile acid metabolism. Gastroenterology 1986; 91: 1007-18.

36 Nilsell K, Angelin B, Leijd B, Einarsson K. Comparative effects of ursodeoxycholic acid and chenodeoxycholic acid on bile acid kinetics and biliary lipid secretion. Gastroenterology 1983; 85: 1248-56.

37 Ponz de Leon M, Carulli N, Loria P, Jori R, Ziromi F. Cholesterol absorption during bile acid feeding. Effect of ursodeoxycholic acid administration. Gastroenterology 1980 78: 214-9.

38 Hardison WGM, Grundy SM. Effect of ursodeoxycholate and its taurine conjugate on bile acid synthesis and cholesterol astroenterology 1984; 87: 130-5.

39 Leiss O, von Bergmann K, Streicher U, Strotkoetler H. Effect of three different $\alpha$-hydroxy bile acids on intestinal absorp-

40 Jüngst D, Brenner G, Pratschke E, Paumgartner G. Low-dose ursodeoxycholic acid prolongs cholesterol nucleation time in gallbladder bile of patients with cholesterol gallstones. f Hepatol 1989; 8: 1-6.

41 Tazuma S, Sasaki H, Mizuno S, et al. Effect of ursodeoxycholic acid administration on nucleation time in human gallbladder bile. Gastroenterology 1989; 97: 173-8.

42 Bickerstaff KJ, Moosa AR. Effects of resection or bypass of the distal ileum on the lithogenicity of bile. Am $\mathcal{F}$ Surg 1983; 145: $34-40$.

43 Pitt HA, Lewenski MA, Muller EL, Porter-Frink V, Den Besten L. Ileal resection-induced gallstones: altered bilirubin or cholesterol metabolism. Surgery 1984; 96: 154-62. 